\title{
Portable System for Coastal Fishpond Water Quality Telemonitoring Continuously
}

\author{
Heru Supriyono $^{1}$, Aldi Majid ${ }^{1}$, Kun Harismah ${ }^{2}$ \\ ${ }^{1}$ Department of Electrical Engineering, Universitas Muhammadiyah Surakarta, Indonesia, \\ Heru.Supriyono@ums.ac.id, D400150121@student.ums.ac.id \\ ${ }^{2}$ Department of Chemical Engineering, Universitas Muhammadiyah Surakarta, Indonesia, \\ Kun.Harismah@ums.ac.id
}

\begin{abstract}
The environmental quality of fishpond including water and surrounding air are very important to be monitored because it affects the health of the fish which could lead to the high death rate. The purpose of this study is to measure the variables of water and air quality of the fishpond automatically then to store the measurement data on the database and display them continuously on a computer or smartphone. The developed instrument was tested on monitoring water and air quality in fish ponds in coastal areas. The test results for each measurement showed the telemonitoring system per part worked well. The results of $\mathrm{pH}$ measurement by telemonitoring have an average error percentage of $1.87 \%$ when compared to commercial measuring instruments namely PH-009 DMT while the results of testing the measurement of salinity levels show the telemonitoring system has an average error of $1.89 \mathrm{ppt}$ or equivalent to $5.67 \%$ compared to the results of measurements using a commercial measuring instrument TDS Meter. The results of temperature and ammonia gas measurements showed that the developed telemonitoring system works stably without any drastic change in the measurement results when tested in a stable environment. Furthermore, the system was able to provide notifications via the Telegram application bot to the smartphone if there is a parameter that exceeds the maximum threshold value.
\end{abstract}

Key words: Ammonia monitoring, environmental monitoring, internet of things, water quality monitoring.

\section{INTRODUCTION}

Highlight Water quality is an important factor in all daily life including fish health. Some parameters of water physical-chemical factors that affect water quality for fish life include power of Hydrogen $(\mathrm{pH})$, total dissolved solid, nitrite, nitrate, phosphate, ammonium, electrical conductivity, and total hardness [1]. Power of Hydrogen $(\mathrm{pH})$ is a measure that shows the acidity of a substance, including liquid. The $\mathrm{pH}$ value is expressed in terms of a number between 0 (acid) to 14 (base). A common process, monitoring water quality is done manually, that is, samples are taken and then tested in a laboratory either chemically or by using an equipment. The disadvantage of manually monitoring water quality is that water quality conditions cannot be monitored continuously in real time.

The fisheries business has enormous potential in the world in general and in Indonesia in particular. This refers to the estimated data on world fish consumption per capita in 2021 to be 19.6 kilograms [2]. In Indonesia, fish consumption per capita per year has reached $31.5 \mathrm{~kg}$. In 2011, fish production from freshwater aquaculture accounted for 1.1 million tons of a total of 12.39 million tons of Indonesia's national fish production (including products from sea catches, marine aquaculture, brackish water cultivation, and freshwater aquaculture). With the consumption of fish that tends to rise, it is necessary to increase the production of aquaculture fish so that the economic potential of freshwater fish farming will also be even greater.

One of the fish cultivated in fresh water that has a high consumption in the community is Tilapia (Oreochromis $s p$ ). Tilapia is easily cultivated, including fishponds in coastal areas. Tilapia has a variety of advantages including in dealing with fluctuating changes in salinity which is able to survive in the range of salinity between $0-35$ parts per thousand (ppt) and also its rapid growth. The characteristics of the fishponds in the coastal area is that the water in the ponds has varying levels of salinity during the day and night which is affected by tides, i.e. at night the sea level rises so that sea water will enter the land including the fishpond thus increasing the salinity level of the pond water while in the morning until the afternoon the surface of the sea water will recede so water from the land returns to the sea which causes the level of water salinity in the pond to decrease.

The quality of fish pond water will greatly support the health and growth of fish. Water quality that does not meet the requirement will lead to inefficient growth of fish or even 
cause death of fish [3] so that it will cause yields that are not as expected, thereby reducing farmers' profits or even harming farmers. For the purposes of fish farming, water quality must be continuously monitored so that it is possible to maximize fish growth and minimize losses due to stunted fish growth or even death. Electronic systems has the potential to be applied to enable water quality monitoring to be carried out continuously.

An electronic system collaborated with computer networks, known as the internet of things (IoT), emerges as the beneficial technology to solve many problems. Using IoT means it is possible to connect the electronic instruments using internet technology so that it could be monitored or even controlled remotely and continuously in real time. IoT technology has been proposed in many areas by researchers such as health care monitoring [4]. In the environment-related areas, IoT has been proposed for weather monitoring [5], water quality monitoring [6] and for real time bridge condition monitoring and early warning system [7].

The development of a water quality monitoring system based on an electronic system attracted the attention of researchers. Bokingkito and Llantos [8] described the results of their research on electronic water temperature monitoring, the results of which can be monitored from an Android smartphone application. The results of research on monitoring water quality with a wider range of parameters are described in [9] where the parameters measured include $\mathrm{pH}$, total dissolved solid, dissolved oxygen, water temperature, and turbidity. Each parameter was detected and measured using a sensor. The measurement results were sent to mobile devices using short message services (SMS). Similar research results but using wireless sensor network (WSN) technology were reported in [10], i.e. they used Zigbee protocol-based instruments to monitor temperature, dissolved oxygen, $\mathrm{pH}$, and water level where the system was then tested on a miniature pool. Similar research was also reported in [11]. Furthermore there are still some research results on monitoring water quality that were reportedly built based on the Zigbee protocol.

Based on observations in micro-scale intensive freshwater aquaculture ponds in the coastal area, it can be seen that fish farmers have not measured the quality of pond water. Pond water quality that is not measured causes farmers to have no data so that it is not possible for farmers to analyze whether the quality of pond water is an ideal condition for fish farming or not. Based on the description above, the formulation of the problem resolved in this publication is an electronic water quality monitoring tool which can be used to monitor water and air quality continuously to be applied to freshwater fish farming ponds in coastal areas.

\section{MATERIALS AND METHOD}

\subsection{System Architecture}

Water and air quality telemonitoring systems are designed using NodeMCU microprocessor as data processing and communication media based on computer networks or known as the internet of things (IoT). NodeMCU will receive and process data from the $\mathrm{pH}$ probe sensor, salinity TDS sensor, MQ-137 sensor, and DS18B20 sensor. Then, the data processed by the NodeMCU microprocessor are displayed on a $16 \times 2$ LCD viewer and sent wirelessly to be displayed via the website. When the water parameter value read by the microprocessor exceeds the threshold, NodeMcu will send a warning message or notification through an intermediary bot of Telegram application. Overall, the system architecture is presented in the block diagram which can be seen in Figure 1.

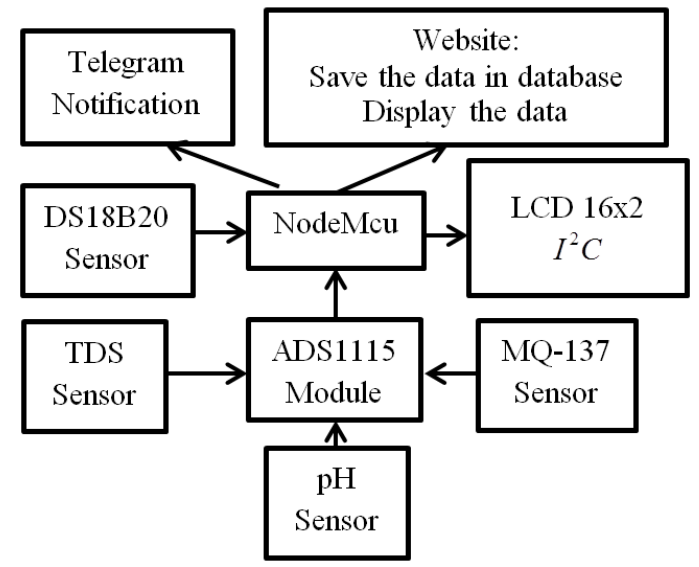

Figure 1: Block Diagram Representing the Overall System Architecture

The proposed system architecture in this article is different from the results reported by other studies, for example in [12] where the researchers used the architecture concept of multiple sensor nodes in one pool. In addition, this publication differs from the publication of research results in [13] where they used sensors to measure $\mathrm{pH}$ and dissolved oxygen (DO) where the results were displayed on computers directly connected to Arduino.

Another special feature of the system in this article is the existence of a bot-based notification system with the Telegram social media application that is if there are parameters that are of higher value than the maximum threshold. This is different from the notification system on water and air quality monitoring reported by other researchers such as using short message services (SMS) [14] and by using web-based notifications/Web Notification Services (WNS) [15].

The $\mathrm{pH}$ sensor probe used has a section dipped in water which is then connected to a cable equipped with a Bayonet Neill Concelman (BNC) connector. The BNC connector will convert the reading data from the acidity level into analogue voltage. This analogue voltage data is then entered at the analogue input pin on the NodeMCU microprocessor. 
Total dissolved solids (TDS) indicate levels of solids both organic and inorganic in liquids which in the context of this study are in fish pond water. Solid objects here include everything other than pure water molecules such as minerals, salts, and other organic substances. Because the research took a case study in a freshwater fish pond in the northern coast of Java, where due to abrasion and tidal water, salty sea water enters the fish pond, the TDS referred to in this study is focused on salinity or the level of salt content in pond water. This sensor can operate using a reference input voltage of 5 Volt Direct Current (DCV). The sensor will produce an analogue output voltage which is then sent to the NodeMCU microcontroller via the analogue pin.

Ammonia in water is a toxic substance that greatly affects the health of fish causing fish not be able to digest food properly which can lead to death [16]. In pond water, the main determinants of ammonia gas levels are effluents from factories that enter the pond and the excrement produced by the fish itself. In addition to pond water, high levels of ammonia gas in the air around the fish pond is feared to have a bad effect on fish, that is poisonous when inhaled by fish or dissolved when there is rain so it is feared that it will cause pond water quality to decrease. The MQ family gas sensor is a popular commercial gas sensor and is widely used by researchers to build off-the-shelf systems such as the MQ-135 sensor which was used to detect the air pollutant in chicken coop [17], and MQ-2 sensor which was used to detect the presence of flammable gases in an environment [18]. This publication uses MQ-137. The MQ-137 sensor has 4 pins, namely VCC (connected to 5 direct current volt (DCV) external voltage source), GND (connected to the ground), A0 (connected to analogue output), and D0 (the digital output).

The DS18B20 sensor is a sensor that has a digital signal output because it already has a 12-bit internal analogue to digital converter (ADC). The DS18B20 sensor requires a 5 DCV reference voltage. The DS18B20 sensor has accuracy or is able to respond to the smallest changes by producing an output of equal to 0.0012 Volts. DS18B20 sensor has an integrated circuit (IC) with three legs which are the sensor pins namely: ground (GND), reference voltage (VDD), and the resulting output data. The DS18B20 sensor can work in two modes namely normal power mode and parasite power mode. In this publication the DS18B20 sensor was operated in normal power mode where resources are obtained from the $3 \mathrm{~V}$ NodeMcu pin. Then, between the VDD pin and the data is connected with a $4.7 \mathrm{~K} \Omega$ resistor which is useful as a pullup of the data path to ensure the data transfer process runs well.

The three sensors used ( $\mathrm{pH}$ probe sensors, TDS, and MQ-137) require analogue pins as sensor output pins (which also means input pins on NodeMCu, i.e. pins on NodeMcu which are used to receive data output from sensors). However,
NodeMcu only has one analogue pin, A0, so that in this publication the ADS1115 module which is a 16-bit ADC module that can receive a maximum of 4 analog signal inputs has been used. The SDA and SCL pins on the ADS1115 module are connected to D3 and D4 NodeMcu pins respectively, while the VCC and GND pins on the ADS1115 module are connected to $3 \mathrm{~V}$ and GND NodeMcu pins respectively. Then, Pins A0 to A3 on the ADS1115 module are connected to the output pins of the three sensors used, namely the $\mathrm{pH}$ sensor probe, TDS, and MQ- 137.

Furthermore, a 16x2 LCD viewer (which means it can display 16 characters horizontally and two characters vertically) was used to display measurement results so that it can be seen on systems developed directly at close range. Normally the LCD module is controlled in parallel so it requires many pins on the controller side. However, because the number of NodeMcu pins is limited, an additional module was used in this publication, the $I^{2} C$ converter module, so that only two data cable lines were needed, namely the SCL and SDA pins on the $I^{2} C$ converter connected to pins D3 and D4 on NodeMcu. The use of the $I^{2} C$ converter module allows SDA and SCL lines to be connected on the same pin as the ADS1115 module which has the same type of communication as SMBus $\left(I^{2} C\right)$.

\subsection{Software Design}

The software design step was divided into three types of software including software on NodeMcu microcontroller, software on computer/smartphone (i.e. websites for displaying data and NodeMcu for the main computation, software for web for for storing measured data in database and display, and software for notifications using Telegram bot on smartphone. Broadly speaking, the computational process of the telemonitoring system in this publication can be seen in the flowchart diagram in Figure 2.

First of all, the monitoring system will ask for the determination of the desired maximum value of parameters ( $\mathrm{pH}$, salinity, ammonia, and temperature). The maximum value limit was determined based on the observed object which in this article is the parameter value above the ideal value for Tilapia fish. Then, NodeMcu will retrieve data from four sensor readings, namely $\mathrm{pH}$, salinity, ammonia, and temperature. The sensor readings were then processed by NodeMcu and: (1) be stored in a database and displayed on the web and (2) displayed on the LCD viewer. Furthermore, NodeMcu compares whether the actual values of the four parameters are above the maximum limit, if any, NodeMcu will send a warning message through the Telegram application, if not, it will finish or read the next sensor reading. 


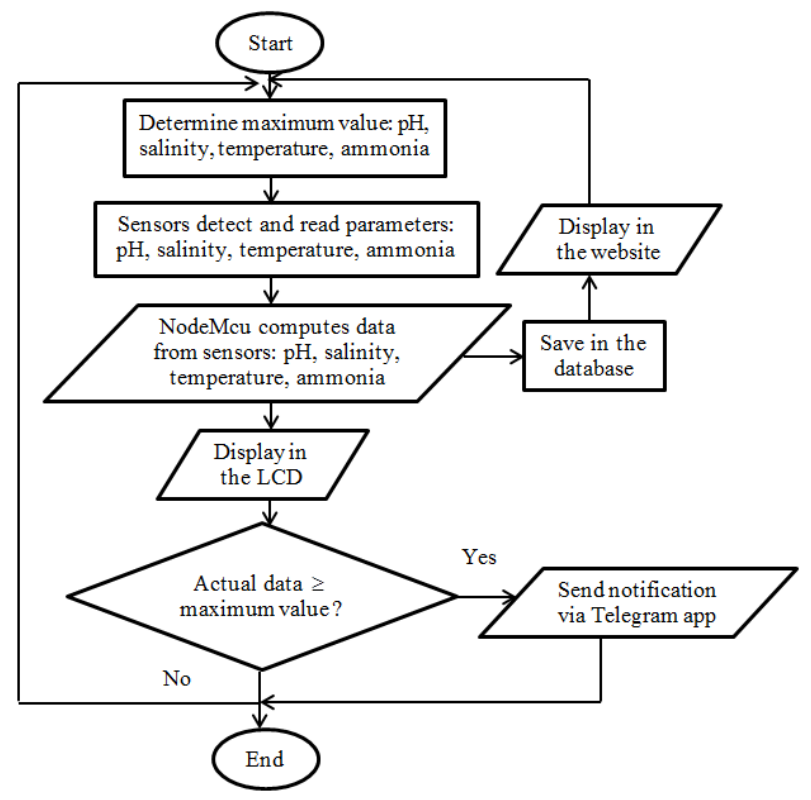

Figure 2: Flowchart Representing the Computation of Telemonitoring System

\subsection{Physical Construction Design}

The telemonitoring system construction developed in this publication was made in the form of ship-shaped 1.2 millimeters thick galvanized plates. Under the plate there is a PVC pipe with a diameter of 1 inch which is useful as a float and makes the area under the ship to be high so that the sensor can be exposed to water and function properly. The overall system layout design that is made can be seen in Figure 3. The hardware series of all components such as NodeMcu, ADS1115 modules, header pins, LCD display modules, and power banks are placed in acrylic boxes and placed inside the ship construction. The PCB circuit gets a $5 \mathrm{DCV}$ coming from the USB Female connector pin which is connected to the USB power bank output. Furthermore NodeMCu also gets voltage from the power bank. The sensor is connected via a header pin on the PCB circuit and placed outside the acrylic box. In Figure 3 there are points $\mathrm{A}, \mathrm{B}, \mathrm{C}$ and $\mathrm{D}$, each of which is the location of the TDS sensor, the DS18B20 temperature sensor, the $\mathrm{pH}$ probe sensor, and the MQ-137 ammonia sensor respectively. The actual appearance of the obtained telemonitoring system construction can be seen in Figure 4.

Ship-shaped construction that can float on the surface of water makes this system can be moved (moveable) in the entire pond area so that it can measure the levels of four parameters namely $\mathrm{pH}$, salinity, temperature, and ammonia at the desired points. This moveable construction differs from architecture that had been published by researchers for example architecture where sensors are placed statically at one point of fishpond in [19] or also placed statically at one point for applications in monitoring water quality in a broad natural environment [20].

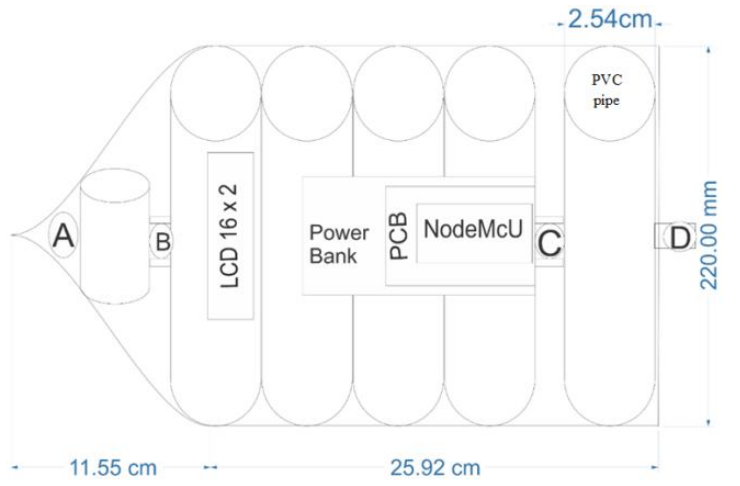

Figure 3: Layout Design of Developed Telemonitoring System Construction

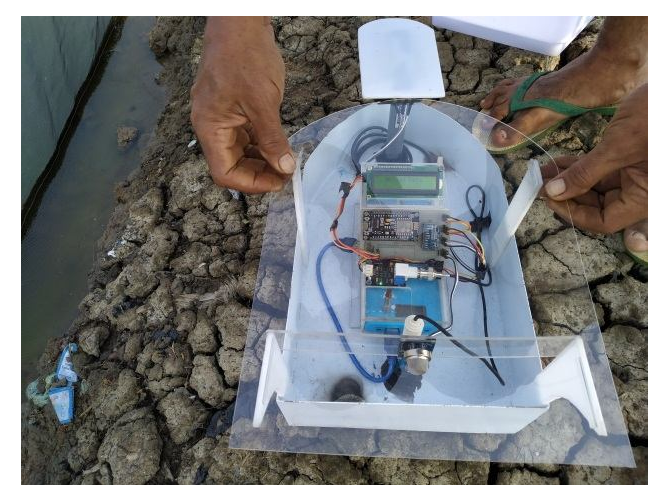

Figure 4: Actual Appearance of Resulted Telemonitoring System

\section{RESULTS AND DISCUSSION}

\subsection{Callibration Process of $\mathrm{pH}$ Probe Sensor and $\mathrm{pH}$ Measurement Testing}

Before using the sensor, in order to work properly, the sensor requires a calibration process. The first step of the calibration process on the $\mathrm{pH}$ sensor probe was to briefly connect the core of the BNC connector to the edge of the connector or probe then upload the program so that a voltage value was obtained. This voltage value will be used as a voltage reading that was read at normal $\mathrm{pH}(\mathrm{pH} 7)$. When tested using a liquid with a normal $\mathrm{pH}(\mathrm{pH} 7)$, normally the sensor should produce a $\mathrm{pH}$ value equal to 7 but if there was a difference it will be a $\mathrm{pH}$ offset value. After the sensor calibration was completed successfully and the sensor was used in the monitoring system, the next step was to conduct a test by comparing the results with commercial measuring instruments on the market which in this publication was the PH-009 Digital Meter Tester (DMT). This comparison was done to find out whether the $\mathrm{pH}$ sensor probe data was valid or not. Tests were carried out on a solution of water with a volume of 250 milliliters which have a $\mathrm{pH}$ value of 7 and 4 . The difference between the results of measurements between using the telemonitoring system developed and by using PH-009 DMT $\left({ }^{E r r o r} r_{p H}\right)$ and the percentage of error was calculated using (1) and (2). 
Heru Supriyono et al., International Journal of Emerging Trends in Engineering Research, 8(9), September 2020, 5163 - 5170

$$
\begin{aligned}
& \text { Error }_{p H}=\left|p H_{D M T}-p H_{T S}\right| \\
& \text { PE }_{p H}=\frac{\text { Error }_{p H}}{p H_{D M T}} \times 100 \%
\end{aligned}
$$

where $p H_{D M T}$ was the result of $\mathrm{pH}$ measurement using PH-009 DMT, $p H_{T S}$ was the result of measuring $\mathrm{pH}$ using a developed telemonitoring system, and $P E_{p H}$ was the error percentage value.

The $\mathrm{pH}$ measurement test was repeated to show that the results were stable. The results of testing the $\mathrm{pH}$ measurements are shown in Tables 1 and 2 for solution with pH 7 and 4 respectively.

Table 1: $\mathrm{pH}$ measurement testing results for solution of water with $\mathrm{pH} 7$

\begin{tabular}{|c|c|c|c|c|}
\hline No & $p H_{D M T}$ & $p H_{T S}$ & Error $_{p H}$ & $P E_{p H}$ \\
\hline 1 & 7.00 & 6.84 & 0.16 & 2.29 \\
\hline 2 & 6.89 & 7.00 & 0.11 & 1.60 \\
\hline 3 & 7.00 & 7.00 & 0.00 & 0.00 \\
\hline 4 & 7.01 & 7.15 & 0.14 & 2.00 \\
\hline 5 & 7.00 & 7.09 & 0.09 & 1.29 \\
\hline 6 & 7.01 & 7.03 & 0.02 & 0.29 \\
\hline 7 & 7.00 & 7.00 & 0.00 & 0.00 \\
\hline 8 & 6.96 & 7.00 & 0.04 & 0.57 \\
\hline 9 & 6.99 & 7.00 & 0.01 & 0.14 \\
\hline 10 & 7.02 & 7.06 & 0.04 & 0.57 \\
\hline$p H_{A_{i}}$ & 6.99 & 7.02 & 0.06 & 0.88 \\
\hline
\end{tabular}

Table 2: $\mathrm{pH}$ measurement testing results for solution of water with $\mathrm{pH} 4$

\begin{tabular}{|c|c|c|c|c|}
\hline No. & $p H_{D M T}$ & $p H_{T S}$ & Error $_{p H}$ & $P E_{P H}$ \\
\hline 1 & 4.01 & 4.01 & 0.00 & 0.00 \\
\hline 2 & 4.05 & 4.01 & 0.04 & 0.99 \\
\hline 3 & 4.00 & 3.78 & 0.22 & 5.50 \\
\hline 4 & 4.02 & 3.84 & 0.18 & 4.48 \\
\hline 5 & 4.01 & 3.91 & 0.10 & 2.49 \\
\hline 6 & 4.00 & 4.02 & 0.02 & 0.50 \\
\hline 7 & 4.01 & 4.02 & 0.01 & 0.25 \\
\hline 8 & 3.98 & 4.00 & 0.02 & 0.50 \\
\hline 9 & 4.00 & 3.98 & 0.02 & 0.50 \\
\hline 10 & 4.01 & 3.87 & 0.14 & 3.49 \\
\hline 11 & 4.04 & 4.01 & 0.00 & 0.00 \\
\hline$p H_{A v}$ & 4.01 & 3.94 & 0.08 & 1.87 \\
\hline
\end{tabular}

In testing with a solution of test materials with a $\mathrm{pH}$ value of 7 in Table 1, it can be seen that the values $P E_{p H}$ ranges between 0 and $2.29 \%$ and in repeated measurements testing the average value ( $\left.p H_{A v}\right)$ amounted to $0.88 \%$. As for the results of testing with the $\mathrm{pH} 4$ solution in Table 2 shows that the value ${ }^{P E_{p H}}$ ranges between 0 and $5.5 \%$ so that the value of $p H_{A v}$ is equal to $1.87 \%$. Technically the results of this test showed that the trend of measurement results using the developed telemonitoring system are inline with the trend of measurement results with PH-009 with values $p H_{A v}$ under $2 \%$. Then if the measurement results are seen on $p H_{D M T}$ it can be seen that the measurement results for liquid with a $\mathrm{pH}$ of 7 has a range between 6.89-7.02 (has a variation range of 0.13) compared to the measurement results at $p H_{T S}$ which is between 6.84-7.15 (has a variation range of 0.31). These results show that the developed telemonitoring system is stable and reliable.

\subsection{TDS/Salinity Measurement Testing}

TDS measurement testing which in this publication is salinity was done by comparing the results of measurements of salinity between using the designed telemonitoring system and by using commercial measuring tools in the market, the TDS Meter. This test was carried out to determine trends in measurement results to understand the reliability of the developed telemonitoring system. Testing was done by measuring the salt content in seawater samples taken from sea water in the northern coast of Java island with a volume of $250 \mathrm{ml}$. Error values and error percentages were calculated using (3) and (4) which are in principle similar to (1) and (2).

$$
\begin{aligned}
& \text { Error }_{S}=\left|S_{T D S M}-S_{T S}\right| \\
& P E_{S}=\frac{\text { Error }_{S}}{S_{T D S M}} \times 100 \%
\end{aligned}
$$

where ${ }^{\text {Error }}{ }_{S}$ is the difference in the value of the measurement of salinity, $S_{T D S M}$ is the salinity value measured from a commercial TDS Meter, ${ }_{T S}$ is the salinity value measured by the developed telemonitoring system, and $P E_{S}$ is the percentage of error value. Salinity level is expressed in parts per thousand (ppt). Salinity measurement tests were done repeatedly to find out the reliability of the measurement results. The results of the measurement test of salinity levels are shown in Table 3.

Table 3: Salinity measurement testing results

\begin{tabular}{|c|c|c|c|c|}
\hline No. & $S_{\text {TDSM }}$ & $S_{T S}$ & Error $_{S}$ & $P E_{S}$ \\
\hline 1 & 33.42 & 31.20 & 2.22 & 6.64 \\
\hline 2 & 34.01 & 31.07 & 2.94 & 8.64 \\
\hline 3 & 33.20 & 31.51 & 1.69 & 5.09 \\
\hline 4 & 31.69 & 31.03 & 0.66 & 2.08 \\
\hline 5 & 32.34 & 30.29 & 2.05 & 6.34 \\
\hline 6 & 33.52 & 31.76 & 1.76 & 5.25 \\
\hline$S_{A v}$ & 33.03 & 31.14 & 1.89 & 5.67 \\
\hline
\end{tabular}


Heru Supriyono et al., International Journal of Emerging Trends in Engineering Research, 8(9), September 2020, 5163 - 5170

The measurement test results in Table 3 showed that the trend of measurement results using developed telemonitoring system were in harmony with the measurement results using a commercial TDS Meter with percentage error value $\left(P E_{S}\right)$ in the range of $2.08 \%-8.64 \%$ and, if calculated, average value $\left(S_{A v}\right)$ was equal to $5.67 \%$. From the measurement results themselves, the measurement using TDS meters ( $\left.S_{T D S M}\right)$ has results with a range between 31.69 and 33.52 ppt or with the largest difference value of $1.83 \mathrm{ppt}$ while the measurement results using the developed telemonitoring system $\left({ }^{S_{T S}}\right)$ has a measurement range between 30.29 and 31.76 ppt which shows the measurement variation range of $1.47 \mathrm{ppt}$. Based on the results of this test, it can be noted that the telemonitoring system showed reliable performance.

\subsection{Temperature Measurement Testing}

DS18B20 temperature sensor performance testing in water temperature measurements were carried out on hot and cold water objects each with a volume of $250 \mathrm{ml}$. The test was repeated in the period of less than five minutes so that the water temperature was still relatively the same. The results of temperature measurements can be seen in Table 4. The measurement results in table 4 showed that the measurement range for hot water is between $69.12{ }^{\circ} \mathrm{C}$ and $70.53{ }^{\circ} \mathrm{C}$ (with a measurement variation of $1.41{ }^{\circ} C$ ) while the measurement results for cold water show the measurement range is between $11.26{ }^{\circ} \mathrm{C}$ and $11.94{ }^{\circ} \mathrm{C}$ (with a measurement variation of $0.68{ }^{\circ} \mathrm{C}$ ). It can be seen from the results of this test that there are no drastically changed measurement results so that the performance of the developed telemonitoring system is stable.

Table 4: Temperature testing results for hot and cold water

\begin{tabular}{|c|c|c|}
\hline No. & Hot $\left({ }^{\circ} \boldsymbol{C}\right)$ & Cold $\left({ }^{\mathrm{O}} \boldsymbol{C}\right)$ \\
\hline 1 & 70.32 & 11.87 \\
\hline 2 & 69.47 & 11.81 \\
\hline 3 & 69.12 & 11.94 \\
\hline 4 & 70.07 & 11.32 \\
\hline 5 & 70.53 & 11.26 \\
\hline 6 & 69.8 & 11.63 \\
\hline Average & 69.89 & 11.64 \\
\hline
\end{tabular}

\subsection{Ammonia Gas Measurement Testing}

Ammonia gas in the daily home environment is produced by the secretion of the human digestive system such as from urine. For the initial stage of testing this block, due to the difficulty of getting ammonia gas for the testing material, the test was carried out by placing the telemonitoring system in the bathroom/toilet where senses of odor produced by the impurities, from example urine, are partly generated from ammonia gas. Telemonitoring systems are placed in two different rooms alternately where the senses have different levels of odor. The test was done repeatedly with the duration of ammonia gas detection data retrieval for one minute. The purpose of this test is to find out whether the MQ- 137 sensor can detect the presence of ammonia gas and whether the output of computed NodeMcu is in ppm units or still in voltage. The results of testing the MQ137 sensor presented in the Table 5 showed that the MQ-137 sensor used in the telemonitoring system has succeeded in detecting the presence of ammonia gas produced by NodeMcu which is already in ppm. In testing results for every room, it can be seen that the measurement results showed almost the same value without any major changes. This indicates that the sensor and telemonitoring system work stably and reliably.

Table 5: Detection and measurement testing results of ammonia gas

\begin{tabular}{|c|c|c|}
\hline \multirow{2}{*}{ No. } & \multicolumn{2}{|c|}{ Location } \\
\cline { 2 - 3 } & Room 1 & Room 2 \\
\hline 1 & 5.31 & 1.12 \\
\hline 2 & 5.24 & 1.56 \\
\hline 3 & 5.86 & 3.22 \\
\hline 4 & 5.18 & 3.03 \\
\hline 5 & 4.49 & 1.21 \\
\hline Average & 5.22 & 2.03 \\
\hline
\end{tabular}

\subsection{Telemonitoring System Testing in Actual Environment}

Testing the whole telemonitoring system in the actual environment was carried out by taking place on the Tilapia fishpond in the northern coast of Java Island, which is located in Pekalongan Regency, Central Java Province, Indonesia. This area was chosen as a case study place because many people cultivate Tilapia fish on the ponds and the location of the ponds which are very close to the shoreline so that the salinity levels in the pond water go up and down while the average farmers have not used technology to monitor water quality in their ponds yet. If the test is successful, this telemonitoring system can be used as an inexpensive and accurate alternative technology to monitor pond water quality so that it supports the success of Tilapia fishpond farmers. The test was carried out by placing a ship-shaped telemonitoring system to sail in the pond area which can then be moved manually such as being pushed with logs or pulled with wire so that it can explore the entire pond area to measure parameters at the desired points. The actual condition of actual environment testing is shown in Figure 5.

Testing was conducted for the entire functional of telemonitoring system including all sensors, storage system or database, the viewer system on the computer and notifications using the Telegram social media application. 
Ideally the test should be carried out all the time i.e. for 24 hours continuously to find out the performance of the telemonitoring system because during the afternoon, night to morning tide sea levels so that salinity levels will be high whereas in the morning to afternoon the salinity levels will drop due to low tide. However, due to constraints on access to the field and difficulties in providing electricity resources for telemonitoring, security and permission, the test was carried out during normal working hours, which was between $7 \mathrm{am}$ and $4 \mathrm{pm}$.

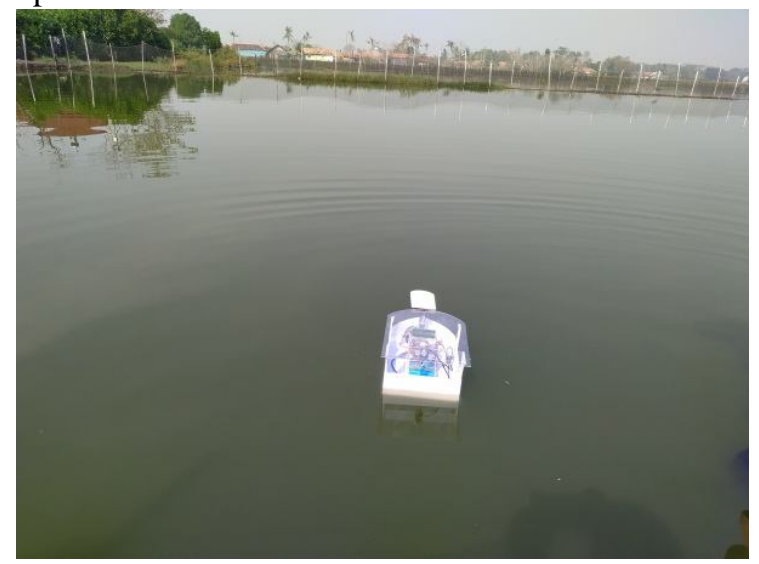

Figure 5: Actual Condition of Telemonitoring System Testing in the Fishpond

Tests are carried out repeatedly to ensure the system working stably and accurately. Samples of overall system test results during one day of testing are shown in Table 6.

Table 6: Whole telemonitoring system testing result on Tilapia fishpond for one day period ( $\mathrm{S}=$ salinity, $\mathrm{A}=\mathrm{Ammonia}$,

\begin{tabular}{|c|c|c|c|c|c|c|}
\hline No & Time & $\mathbf{p H}$ & $\begin{array}{c}\text { S } \\
(\mathbf{p p t})\end{array}$ & $\begin{array}{c}\mathbf{A} \\
(\mathbf{p p m})\end{array}$ & $\begin{array}{c}\text { T } \\
\left({ }^{\mathrm{O}} C\right)\end{array}$ & $\mathbf{N}$ \\
\hline 1 & $09: 02: 53$ & 6.61 & 1.11 & 0.48 & 25.56 & No \\
\hline 2 & $09: 03: 05$ & 6.57 & 1.12 & 0.19 & 25.56 & No \\
\hline 3 & $09: 03: 17$ & 6.79 & 1.15 & 0.17 & 25.69 & No \\
\hline 4 & $09: 03: 29$ & 6.74 & 1.14 & 0.16 & 25.69 & No \\
\hline 5 & $09: 03: 42$ & 6.73 & 1.11 & 0.13 & 25.75 & No \\
\hline 6 & $09: 03: 54$ & 6.63 & 1.13 & 0.14 & 25.75 & No \\
\hline 7 & $09: 04: 07$ & 6.62 & 1.07 & 0.09 & 25.75 & No \\
\hline 8 & $09: 04: 19$ & 6.67 & 1.08 & 0.09 & 25.75 & No \\
\hline 9 & $09: 04: 35$ & 6.57 & 1.06 & 0.09 & 25.25 & No \\
\hline 10 & $09: 04: 47$ & 6.77 & 1.12 & 0.10 & 25.25 & No \\
\hline 11 & $14: 06: 23$ & 6.96 & 1.18 & 0.88 & 24.94 & No \\
\hline 12 & $14: 06: 39$ & 6.81 & 1.14 & 0.92 & 25.00 & No \\
\hline 13 & $14: 06: 52$ & 6.95 & 1.18 & 2.47 & 25.00 & Yes \\
\hline 14 & $14: 07: 15$ & 6.80 & 1.14 & 3.33 & 25.00 & Yes \\
\hline 15 & $14: 07: 35$ & 6.80 & 1.14 & 3.78 & 24.94 & Yes \\
\hline 16 & $14: 08: 59$ & 6.82 & 1.14 & 1.93 & 25.62 & Yes \\
\hline 17 & $14: 09: 23$ & 6.82 & 1.14 & 2.15 & 25.69 & Yes \\
\hline 18 & $14: 12: 15$ & 6.82 & 1.14 & 1.73 & 25.69 & Yes \\
\hline 19 & $14: 13: 11$ & 6.80 & 1.14 & 1.60 & 25.19 & Yes \\
\hline 20 & $14: 13: 27$ & 6.80 & 1.14 & 1.60 & 25.19 & Yes \\
\hline
\end{tabular}

The test results in Table 6 showed that the measurement results for $\mathrm{pH}$, salinity levels and water temperatures which are relatively fixed throughout the day because the weather was stable and the sun was shining full (not rain) and also the surface of the sea was receding so that no sea water enters the pond. These results indicate that the telemonitoring system was working stable. For the measurement of ammonia gas levels, the results in Table 6 showed That the telemonitoring system was able to detect changes in ammonia levels above the fishpond. In the testing, the maximum limit of ammonia gas levels in the telemonitoring system was set at $1 \mathrm{ppm}$ so that if the ammonia gas level is equal to or higher than $1 \mathrm{ppm}$ then the system will send a notification to the Telegram application. The test results showed that the telemonitoring system was capable of sending notifications properly. An example of a notification using the Telegram bot application on a smartphone is shown in Figure 6. All parameters in Table 6 were stored in a database placed in the web and the results were displayed continuously in the form of graphics and numbers. The average time delay, the time needed from NodeMcu starting send the measurement results until it was stored in the database was 3.5 seconds, while for sending notifications on a telegram bot was 15 seconds depending on the availability of internet data signals used.

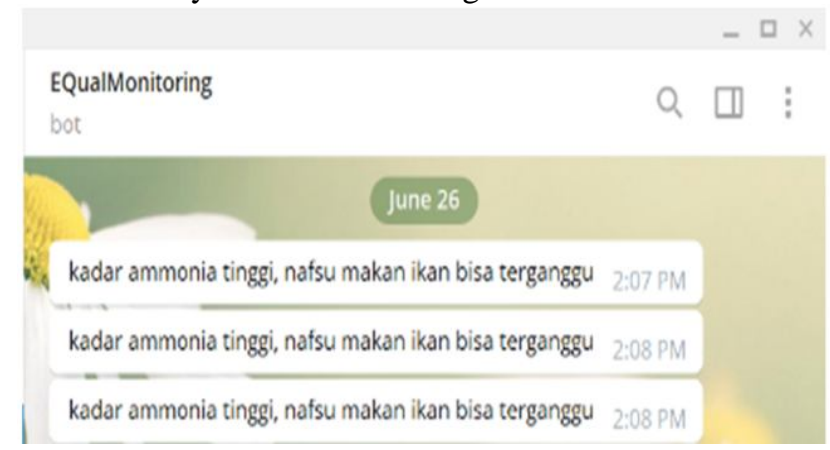

Figure 6: Example of Notification Display Using Telegram Bot Application on a Smartphone: Shows the Level of Ammonia Higher Than the maximum Threshold (User Interface of the Notification was Built in Bahasa Indonesia)

\section{CONCLUSION}

The test results for each measurement showed that the telemonitoring system per part was working well. The results of $\mathrm{pH}$ measurement by telemonitoring have an average percentage error of $1.87 \%$ when compared to commercial measuring instruments namely PH-009 DMT. While the results of testing the measurement of salinity levels show the telemonitoring system has an average error of $1.89 \mathrm{ppt}$ or equivalent to $5.67 \%$ compared to the results of measurements using a commercial measuring instrument TDS Meter. The results of temperature and ammonia gas measurements showed that the developed telemonitoring system works stably without any drastic change in measurement results when tested in a stable environment. The results of overall telemonitoring system testing in the field suggested that telemonitoring system able to detect and measure parameters, display them on the LCD viewer, send them to the database, 
Heru Supriyono et al., International Journal of Emerging Trends in Engineering Research, 8(9), September 2020, 5163 - 5170

display measurement / monitoring data on the web continuously and be able to provide notifications via the Telegram application bot to the smartphone if there are parameters that exceed the maximum threshold value.

\section{ACKNOWLEDGEMENT}

Authors would like to thank to Research and Community Services of Ministry of Research Technology and Higher Education/(DRPM) Kemenristekbrin of Republic of Indonesia for providing research grant under PDUPT scheme year 2020.

\section{REFERENCES}

1. M.-M. Stavrescu-Bedivan, G. V. Scaeteanu, R. M. Madjar, M. S. Manole, A. C. Staicu, F. T. Aioanei, E. F. Plop, G. L. Toba, and C. G. Nicolae. Interactions between fish well being and water quality: a case study from Morii Lake area Romania, Agriculture and Agricultural Science Procedia, vol. 10, pp. 328-339, 2016.

2. Ministry of Marine and Fisheries (Kementrian Kelautan dan Perikanan $(K K P))$, The potential of freshwater aquaculture (Potensi usaha budidaya ikan air tawar), accessed

online:

http://news.kkp.go.id/index.php/potensi-usaha-budidaya -ikan-air-tawar/ , 2015, (20 October 2018).

3. Z. Svobodova, R. Lloyd, J. Machova, and B. Vykusova. Water quality and fish health, EIFAC Technical Paper, 54, Rome, FAO, 1-159, 1993.

4. R. R. Chintala, C. N. S. M. Akhilesh, N. P. P. Ganesh, and $T$ Ravideep. Wireless sensor network for m-healthcare monitoring of human being, International Journal on Emerging Trends in Engineering Research (IJETER), vol. 8, no. 5, pp. 1685-1688, 2020.

5. N. M. Arago, E. A. Galido, M. V. C. Padilla, L. M. Tulin, G. C. Virrey, and J. S. Velasco. Long Range Communication Technology for Weather Buoy, International Journal on Emerging Trends in Engineering Research (IJETER), vol. 8, no. 8, pp. 4399-4404, 2020.

6. M. M. Caranguian, B. B. Abad Jr., and E. B. Panganiban. Tilapia Fishpond Monitoring System with Fishkill Prevention, International Journal on Emerging Trends in Engineering Research (IJETER), vol. 8, no. 8, pp. 4399-4404, 2020.

7. M. Riyansyah, P. B. Wijayanto, B. R. Trilaksono, S. A. Putra, and D. S. Laila. Real Time Bridge Dynamic Response: Bridge Condition Assessment and Early Warning System, International Journal on Advanced Science Engineering Information Technology (IJASEIT), vol. 10 no. 1, pp. 325-330, 2020.

8. P. B. Bokingkito Jr, and O. E. Llantos. Design and Implementation of Real-Time Mobile-based Water Temperature Monitoring System, Procedia Computer Science, vol. 124 (2017), pp. 698-705, 2017.
9. H. Mohammed, and I. Al-Mejibli. Smart monitoring and controlling system to enhance fish production with minimum cost, Journal of Theoretical and Applied Information Technology, vol. 96, no. 10, pp. 2872-2884, 2018.

10. L. Jinfeng, and C. Shun. A ZigBee-based Aquaculture Water Quality Monitoring System, International Journal of $u$ - and e-Service, Science and Technology, vol. 8, no. 10, pp. 367-376, 2015.

11. Y. Xuecun, Z. Chuanqi, K. Linghong, and H. Zhixin. Design of Fishpond Water Quality Monitoring and Control System Based on ZigBee, Journal of Applied Science and Engineering Innovation, vol.2 No.10, pp.385-388, 2015.

12. F. A. Saparudin, T. C. Chee, A. S. Ab Ghafar, H. A. Majid, and N. Katiran. Wireless water quality monitoring system for high density aquaculture application, Indonesian Journal of Electrical Engineering and Computer Science, vol. 13, No. 2, pp. 507-513, February 2019.

13. Z. Harun, E. Reda, and H. Hashim. Real time fish pond monitoring and automation using Arduino, in IOP Conf. Series: Materials Science and Engineering, vol. 340 (2018) 012014, pp. 1-12, 2018.

14. M. Barabde, and S. Danve. Real time water quality monitoring system, International Journal of Innovative Research in Computer and Communication Engineering, vol. 3, no. 6, pp. 5064-5069, June 2015.

15. N. Markovic, A. Stanimirovic, and L. Stoimenov. Sensor web for river water pollution monitoring and alert system, in 12th AGILE International Conference on Geographic Information Science 2009, Leibniz Universität Hannover, Germany, pp. 1-9, 2009.

16. J. A. Hargreaves, and C. S. Tucker. Managing ammonia in fish ponds, South Region Aquaculture Center (SRAC) Publication No. 4603, pp. 1-8, 2004.

17. H. Supriyono, U. Bimantoro, and K. Harismah. Design, construction and testing of portable systems for temperature, humidity and ammonia monitoring of chicken coop, in IOP Conf. Series: Materials Science and Engineering, vol. 771 (2020) 012003, pp. 1-8, 2020.

18. H. Supriyono, E. D. Febriyanto, and K. Harismah. Portable machine to machine system for monitoring temperature and flammable gas of outdoor environment, in AIP Conference Proceedings 2114, vol. 040014 (2019), pp. 040014-1 - 040014-8, 2019.

19. F. E. Idachaba, J. O. Olowoleni, A. E. Ibhaze, and O. O. Oni. IoT Enabled Real-Time Fishpond Management System, in Proceedings of the World Congress on Engineering and Computer Science 2017 Vol I, WCECS 2017, October 25-27, 2017, San Francisco, USA, pp. 1-5.

20. K. A. Mamun, F. R. Islam, R. Haque, M. G. M. Khan, A. N. Prasad, H. Haqva, R. R. Mudliar, and F. S. Mani. Smart Water Quality Monitoring System Design and KPIs Analysis: Case Sites of Fiji Surface Water, Sustainability, vol. 11, no. 7110, pp. 1-21, 2019. 